\title{
Synthesis and Morphological Study of Aminoglycosides-Modified Gold and Silver Nanoparticles
}

\author{
Santosh V. Nalage ${ }^{1}$, Sidhanath V. Bhosale ${ }^{1 * *}$ and Sheshanath V. Bhosale ${ }^{2^{*}}$ \\ ${ }^{I}$ Department of Organic Chemistry, North Maharashtra University, Jalgaon 425001 (MS) India \\ ${ }^{2}$ School of Applied Sciences, RMIT University, GPO Box 2476V, Melbourne, Vic. 3001, Australia
}

\begin{abstract}
We demonstrate new method for the synthesis of gold and silver nanoparticles from pineapple extract. Furthermore, we have studied interactions between nanoparticles (gold and silver) with aminoglycosides such as Kanamycin $\mathrm{A}$, Neomycin. Both nanoparticles were prepared by reducing $\mathrm{AuCl}_{4}$ and $\mathrm{AgNO}_{3}$ using pineapple extract, kanamycin $\mathrm{A}$ and neomycin as both reducing and stabilizing agents respectively. Our new approach shows a clean method of synthesizing gold and silver nanoparticles that exhibit promising morphologies and stability under physiological conditions for several months in powder or aqueous form. Transmission electron microscopy (TEM) was employed to visualize the diameters of nanoparticles.
\end{abstract}

Keywords: Gold colloids, Silver colloids, Pineapple extract, Kanamycin A, Neomycin, TEM, Biomaterial.

\section{INTRODUCTION}

Metallic nanostructures of gold and silver have been studied extensively and are emerging areas in nanoscience and biology because of their unique optical, electronic and magnetic properties [1-3]. Metal nanoparticles (NPs) produced from gold $(\mathrm{Au})$ and silver $(\mathrm{Ag})$ with their binding abilities with biological molecules makes them attractive tool for studying molecular interactions [4]. The most characteristic property as nanoscale building blocks e.g. nanoparticles, nanorods, nanotubes, nanowires lies in their power to induce the formation of aggregated material through "bottom up approach" [5-6]. The aggregation of such nanostructure using surfactants, DNA (deoxyribos nucleic acid) molecules as well as using biotin-streptavidin wells established [7-9]. Various methods have been reported in last two decades for the synthesis of $\mathrm{Au}$ and $\mathrm{Ag}$ nanoparticles, which involved applying reducing agent such as ascorbic acid, $\mathrm{NaBH}_{4}$, microwaves, transmetalation reaction, poly(vinyl pyrrolidone), sodium citrate, seed mediated synthesis, polymeric strands of oleylamine- $\mathrm{AuCl}$ complex and ionic polymers [10-18]. Moreover, recent developments in the synthesis and application of AuNPs have allowed several groups to probe the function of this interesting class of material in a molecular and supramolecular sense [19-25]. Supramolecular selfassembled material of $\mathrm{Au}$ and $\mathrm{Ag}$ nanoparticles was also studied extensively [26]. Literature survey reveals that the assembly of nanoparticles is based on two important factors, first is the shape and size distributions of the particles nanoparticles and second is interactions with organic molecules, which can be well characterize by strong plasmon

*Address correspondence to these authors at the Department of Organic Chemistry, North Maharashtra University, Jalgaon 425001 (MS) India Email: sidhanath2003@yahoo.com and School of Applied Sciences, RMIT University, GPO Box 2476V, Melbourne, Vic. 3001, Australia,

Tel: +61 468839335; Email: bsheshanath@yahoo.com resonance [27]. On the other hand, biological syntheses of metallic nanoparticles are quite attractive because of their simplicity, convenient, uncatalysed and environmentally green method. Recent newly synthetic routes [28-32] clearly indicate that nanoparticle properties such as shape, particle size and stability are comprehensive to work on this methodology. In this regard, the functionalization of the synthesized $\mathrm{Au}$ and $\mathrm{Ag}$ nanoparticles using biomolecules including DNA and proteins has been extensively studied. However, selfassembly of metal nanoparticles with aminoglycosides such as kanamycin A, neomycin has not been explored yet. Aminoglycoside antibiotics constitute a large family of clinically important drugs used in the treatment of gramnegative infections [33]. Aminoglycosides are hydrophilic molecules, consisting of a characteristic, central aminocyclitol linked to one or more amino sugars by pseudoglycosidic bond. Nevertheless, the antibacterial effects of $\mathrm{Ag}$ salts have been well known, most importantly Ag control bacterial growth in variety of applications. Thus, the incorporation of aminoglycosides onto nanomaterial has become interesting field in nanoscience. Furthermore, modified nanomaterials may utilize for better efficiency to facilitate their applications in bioscience and medicine. Herein, we report simple strategy for synthesis of $\mathrm{Au}$ and $\mathrm{Ag}$ nanoparticles utilizing pineapple extract, organic molecules from pineapple extract act as reducing agent in control synthesis of both the nanoparticles. Pineapple contains various components such as thiamine, riboflavin, vitamin $\mathrm{B}$, vitamin $\mathrm{C}$ and $\mathrm{Ca}, \mathrm{Fe}, \mathrm{Mg}, \mathrm{P}, \mathrm{K}, \mathrm{Zn}$, which is beneficial for variety of diseases and most of them found application in nanoscience. In addition, the chemical composition of the pineapple extract may be dependent on the country and area. This may cause the problem for the reproducibility of the experiments this may be improved by the real-life experimental case studies [34-36]. In addition, we have also investigated the role of kanamycin A and neomycin for stabilization of $\mathrm{Au}$ and $\mathrm{Ag}$ nanoparticles in aqueous media (Scheme 1). UV-Vis (Ultraviolet-visible) absorp- 


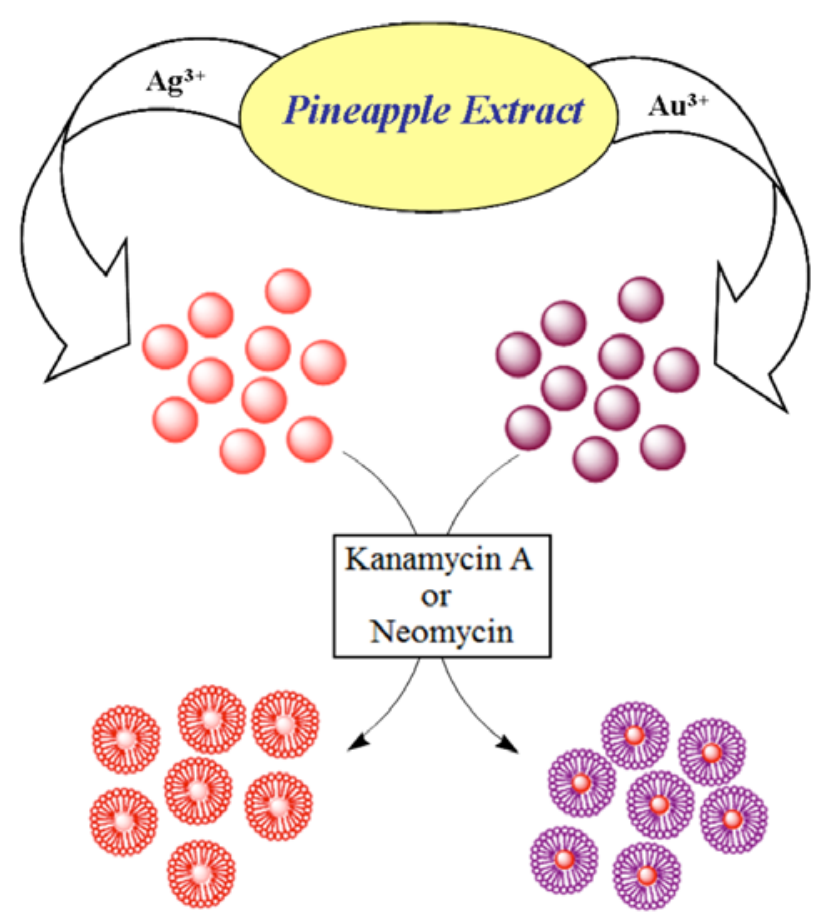

Scheme 1. Schematically representation of the synthesis of Au and Ag nanoparticles and stabilization of nanoparticles with aminoglycosides (kanamycin A and neomycin).

tion, FT-IR (Fourier transform infrared), transmission electron microscopy (TEM) analysis were performed to study size, shapes of the nanoparticles and their interactions with aminoglycosides.

\section{EXPERIMENTAL}

Materials: Gold chloride trihydrate $\left(\mathrm{HAuCl}_{4}\right)$, silver nitrate $\left(\mathrm{AgNO}_{3}\right)$, kanamycin $\mathrm{A}$, neomycin were purchased from Sigma-Aldrich and used without further purification. Milli 'Q' water was used throughout the experiment.

Synthesis: The pineapple extract used in all experiments were prepared by $20 \mathrm{gm}$ of finely cut pieces in flask with $100 \mathrm{ml}$ of Milli-Q water and then boiled the mixture for 10 minutes, finally decanting it. In a typical experiment, $2 \mathrm{ml}$ of $10^{-3} \mathrm{M}$ aqueous $\mathrm{HAuCl}_{4}$ solution was added to $5 \mathrm{ml}$ of above pineapple extract. The reaction mixture was allowed to settle at room temperature. Formation of the particles could be observed from the change of color of reaction mixture. The colorless solution turns violet at the end of the reaction, which is the primary indication of particle formation.

For the stablisation of the nanoparticles with aminoglycosides (Kanamycin A and Neomycin): Mixture of pineapple (5 ml) and $\mathrm{HAuCl}_{4}\left(2 \mathrm{ml}\right.$ of $10^{-3} \mathrm{M}$ aqueous) was treated with aminoglycosides such as kanamycin A or neomycin (5 $\mathrm{ml}$ of $\left.10^{-3} \mathrm{M}\right)$. The color change observed was from yellowish to red within a 10 minutes. Following similar protocol synthesis of silver nanoparticles was carried out using $\mathrm{AgNO}_{3}$ (2 mL of $10^{-3} \mathrm{M}$ solution). Purification of particles was performed by centrifugal filtration at $10,000 \mathrm{rpm}$ for 5 minutes by redissolving residue in milli-Q water and solution was loaded into a centrifugal filter device and was subjected to centrifugation. The process repeated three times until the starting material could no longer be detected by thin layer chromatography (TLC). The products obtained were free of salts and starting material.

UV-vis Absorption and Infra-red Spectroscopy: All stock solutions of gold and silver nanoparticles diluted with sufficient amount of milli 'Q' water and sonicated well before measurement. For spectral measurements, each sample of above solution $(2 \mathrm{~mL})$ was delivered in a cuvette by micropipette. UV-visible absorption spectra were recorded 200 to $900 \mathrm{~nm}$ range on a UV-1601 Shimadzu spectrophotometer. Absorption peaks of functional groups were observed by Fourier-transform Infrared (FT-IR) on Shimadzu Spectrometer DRS-84000 using KBr pellet.

Transmission electron microscopy: Transmission electron micrograph observations of AuNPs and AgNPs samples were made on a Philips model-CM-200, operating voltage $200 \mathrm{kv}$, on resolution $2.4 \AA$. Typically $3-4 \mu \mathrm{L}$ droplets of $A u$ and Ag nanoparticles suspension were deposited on carboncoated 300 mesh copper grids and excess liquid was wicked off with filter paper. TEM analysis was performed to characterize the morphologies of $\mathrm{Au}, \mathrm{Ag}$ aminoglycosidesmodified nanoparticles. All samples dispersed in milli ' $Q$ ' water.

\section{RESULTS AND DISCUSSION}

The pineapple extract $(\mathrm{pH}=3)$ collect by refluxing small pieces of ripped pineapple in milli ' $Q$ ' water. The Colloidal $\mathrm{Au}$ and $\mathrm{Ag}$ nanoparticles precipitated by addition of pineapple extract to $10^{-3} \mathrm{M}$ aqueous $\mathrm{HAuCl}_{4}$ and aqueous $\mathrm{AgNO}_{3}$ at room temperature respectively. After centrifugation, the particles were redispersed in water and produced perfectly stable colloidal solutions in water. $\mathrm{Au}$ and $\mathrm{Ag}$ nanoparticles were prepared using pineapple extract with various functional groups (amino, thiol, carboxyl, and hy- 

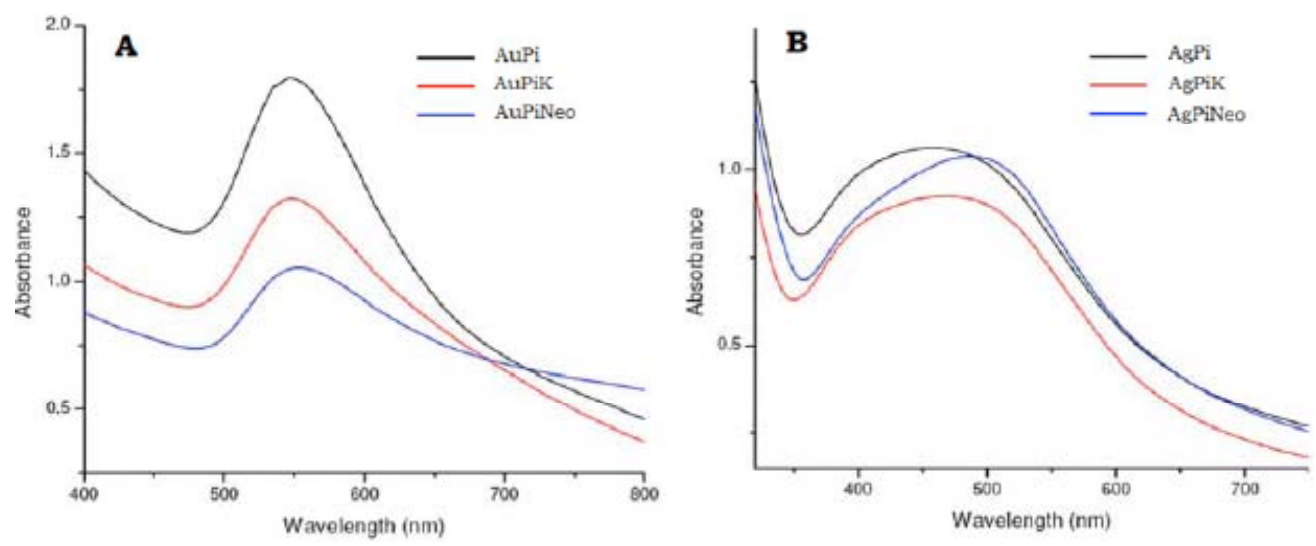

Fig. (1). Normalized spectra of $\mathrm{Au}^{0}$ and $\mathrm{Ag}^{0} \mathrm{NPs}$ prepared using pineapple extract (black) with increasingly red shifted longitudinal plasmon bands, synthesized using kanamycin (red) A and neomycin (neomycin) respectively.

droxyl). It is believed that the functional groups present at the pine apple extract acts as a reducing agent for $\mathrm{AuCl}_{4}$ and $\mathrm{AgNO}_{3}$ in the synthesis of nanoparticles. In particular, upon reduction of $\mathrm{AuCl}_{4}$ and $\mathrm{AgNO}_{3}$ the color of solution changed from colorless to violet in case of AuNPs and while red in the case of AgNPs respectively. Primarily the bioconjugates prepared in this synthesis were analyzed by UV/Vis spectroscopy. The UV-vis absorption spectrum of sample after $4 \mathrm{~h}$ in water produced the plasmon absorption band at $547 \mathrm{~nm}$ and $452 \mathrm{~nm}$ (Fig. 1) for AuNPs and AgNPs respectively, which indicates formation of $\mathrm{Au}$ and $\mathrm{Ag}$ nanoparticles with well morphology, even keeping reaction mixture for longer time does not shows any changes in absorption indicating completion of the reaction with control growth of NPs. The UV/Vis spectra of both the nanoparticle solutions remained unchanged even after months, indicating particles stable in water and show no sign of aggregation. In general AgNPs usually have an absorption maximum at $410 \mathrm{~nm}$ but particles produced via pineapple extract reduction the plasmon band shifted to the longitudinal plasmon band $(452 \mathrm{~nm})$. This broadening and increase in plasmon resonance at higher wavelength indicates agglomerated nanoparticles.

To visualize exact size and shapes of nanoparticles, TEM analysis is investigated as shown in Fig. (2). TEM analysis clearly shows that most of the $\mathrm{Au}$ and $\mathrm{Ag}$ nanoparticles were spherical in shape. A few agglomerated nanoparticles were also observed in some places, which may probable due to self-assembly of smaller particles upon prolongation of time. TEM images of $\mathrm{Au}$ and $\mathrm{Ag}$, it is evident that there is variation in particle sizes and the average size estimated was 50 $\mathrm{nm}, 30 \mathrm{~nm}$ for $\mathrm{Au}$ and $\mathrm{Ag}$ and the particles size ranged from $40 \mathrm{~nm}$ for $\mathrm{Au}$ and $24 \mathrm{~nm}$ to $40 \mathrm{~nm}$ for $\mathrm{Ag}$ nanoparticles respectively. Very interestingly, all the prepared $\mathrm{Au}$ and $\mathrm{Ag}$ NPs via pineapple extract are varying in size and shape but formed shapes are stable and clearly distinguish by microscopic analysis.

The stability of nanoparticles is a major issue in nanoscience. In this study, we have investigated stabilization of AuNPs and AgNPs using aminoglycosides (kanamycin A, neomycin). The UV-Vis spectra of solutions of Au-Pi and Ag-Pi were examined after addition of kanamycin $(10 \mathrm{mM})$ and neomycin $(10 \mathrm{mM})$ as shown in Fig. (1). After addition of kanamycin and neomycin, the surface plasmon resonance band is shifted toward lower intensity compared with $\mathrm{Au}$



Fig. (2). TEM images and related selected-area diffraction pattern of polydisperse $\operatorname{Au}^{0}(\mathbf{a}, \mathbf{b}, \mathbf{c})$ and $\operatorname{Ag}^{0}(\mathbf{d}, \mathbf{e}, \mathbf{f})$ synthesized using pineapple extract and modified particles with kanamycin $\mathrm{A}$ and neomycin respectively.

pineapple nanoparticles (Au-Pi) at $547 \mathrm{~nm}$. Decrease in the plasmon resonance indicates change in size and shape of nanoparticles (Fig. 1). Kanamycin A and neomycin acted as stabilizing and have ability to bind the bioconjugates via hydrogen bonding, electrostatic interaction. Excess aminoglycosides can be easily removed from sample by repeated washing and centrifugation with water. Moreover, kanamycin (AuPiK) and neomycin (AuPiNeo) modified nanoparticles were analyzed by TEM (Fig. 2). The aminoglycoside modified $\mathrm{Au}$ nanoparticles were polydispersed (nanorod, 

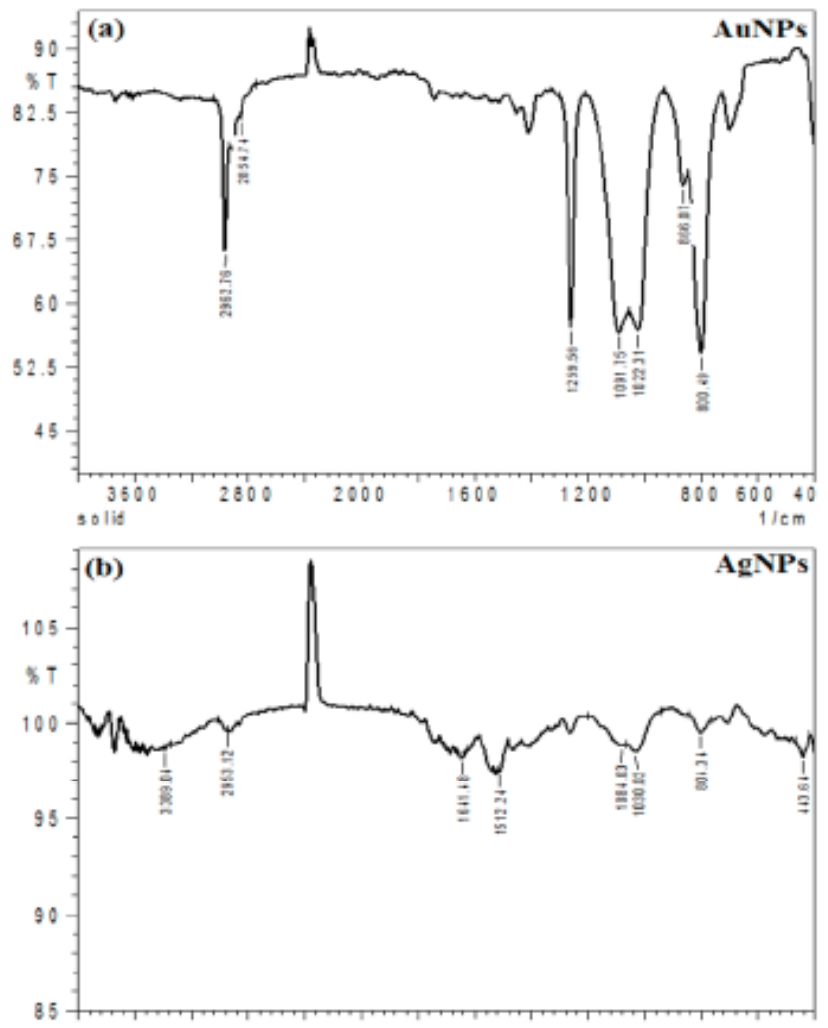

Fig. (3a). Shows the IR absorption spectrum of gold nanoparticles and (b) Silver nanoparticles synthesize from pineapple extract.

nanotriangles, pentagonal, spherical and nanoprism) with size ranging from $5 \mathrm{~nm}$ to $80 \mathrm{~nm}$. In the case of aminoglycoside modified silver nanoparticles, the plasmon absorption band was shifted at $469 \mathrm{~nm}, 470 \mathrm{~nm}$ for $\mathrm{AgPiK}$ and $\mathrm{Ag}$ PiNeo respectively. The surface plasmon resonance band is shifted toward a longer wavelength, compared with $\mathrm{Ag}$ nanoparticles $(452 \mathrm{~nm})$. The range of diameters of the particles is varying between $5 \mathrm{~nm}$ to $30 \mathrm{~nm}$ (Fig. 2e and $\mathbf{2 f}$ ).

Furthermore, infrared spectroscopy (FTIR) support formation of the $\mathrm{Au}$ and $\mathrm{Ag}$ nanoparticles (Fig. 3a,b), the absorption bands at 2962, 2854 (C-H stretching), $1770(\mathrm{C}=\mathrm{O}$ stretching), 1480 (C-H bending) and 1259, 1091, 1022 (C-O stretching) $\mathrm{cm}^{-1}$ are observed for gold nanoparticles. Broad absorption bands at 3389 (N-H stretching), 2953 (C-H stretching), 1611 ( $\mathrm{C}=\mathrm{C}$ stretching), 1512 (C-H bending), 1280 (C-O stretching), 1081, $1030(\mathrm{C}=\mathrm{C}$ stretch, primary alcohol, C-O stretch), 801 (C-O stretch, carbonate ion) $\mathrm{cm}^{-1}$. Additional moderate to intense bands in ranges 1600$1300,1200-1000$ and $800-600 \mathrm{~cm}^{-1}$ observe, due to presence of hydroxy compound that the hydrogen-bonded $-\mathrm{OH}$ absorption. The general observation showed the presence of the carbohydrates, sugars, proteins and amino acid constituent of the pineapple extract. FTIR studies obviously evident of that formed AuNPs and AgNPs by organic components from pineapple extract.

The natural source of pineapple extract incorporated with a nanoparticle carrier demonstrated a useful strategy in developing biological applications. The use of natural biocatalytic protocol for the synthesis and fabrication of nanoparticles is the promising field for researchers. Scientist, tech- nologists, and environmentalist all have interest in developing simple, efficient approaches to increase benefits in terms of sensitivity, selectivity, stability and reproducibility of nanoparticles.

\section{CONCLUSION}

We have demonstrated biosynthesis of series of $\mathrm{Au}$ and Ag nanoparticles from pineapple extract and its modification with aminoglycosides (kanamycin A, neomycin) as a stabilizing agent. Results demonstrate that the aminoglycosides play a crucial role in tuning the properties of silver and gold nanoparticles. The modified $\mathrm{Au}$ and $\mathrm{Ag}$ nanoparticles are polydispersed and are much more stable in solution as well as in powder form for longer time. Present biosynthetic protocol is very benifitial for synthesis and shape control of $\mathrm{Au}$ and Ag nanoparticles with unique structural and spectral properties at room temperature in aqueous medium compare to other methods developed so far. However, there are also few limitations with size controlled synthesis, as in some instance AuNPs and AgNPs occurred over a large size range and showed greater agglomeration. This work has specific effects in colloidal science and biological systems. We are currently working on alternative methods for the development of controlled size and dimensions of the particles and their biological application and will published in due course.

\section{ACKNOWLEDGEMENTS}

Financial support from Department of Science and Technology (Grant No. SR/FTP/CS-82-2007), New Delhi is greatly acknowledged. We thank Miss. Princy Patro and Ms. Bharati Varghese SAIF, IIT, Powai, Mumbai and JNCASR, Bangalore for help with TEM measurements.

\section{CONFLICT OF INTEREST}

None declared.

\section{REFERENCES}

[1] Black, C.T.; Murray, C.B.; Strom, R.L.; Sun, S.H. Spin-dependent tunneling in self-assembled cobalt-nanocrystal superlattices. Science, 2000, 290, 1131.

[2] Cao, Y.W.C.; Jin, R.C.; Mirkin, C.A. Nanoparticles with raman spectroscopic. Fingerprints for DNA and RNA detection. Science, 2002, 297, 1536

[3] Fan, H.Y.; Yang, K.; Boye, D.; Sigmon, T.; Malloy, K.; Xu, H.; Lopez, G.P.; Brinker, C. Self-assembly of ordered, robust, threedimensional gold nanocrystal/silica arrays. Science, 2004, 304, 567.

[4] Sadowski, Z. Biosynthesis and application of silver and gold nanoparticles. Silver Nanopart., 2010, 257-276.

[5] Shipway, A.N.; Katz, E.; Willner, I. Nanoparticle arrays on surfaces for electronic, optical, and sensor applications. Chem. Phys. Chem., 2000, $1,18$.

[6] Shenhar, R.; Otello, M. Nanoparticles as Scaffolds and Building Blocks. Acc. Chem. Res., 2003, 36, 549.

[7] Nikoobakth, B.; Wang, Z.L.; EI-Sayed, M.A. Self-assembly of gold nanorods. J. Phys. Chem. B., 2000, 104, 8635.

[8] Dujardin, E.; Hsin, L.-B.; Wang, C.R.C.; Mann, S. DNA-driven self-assembly of gold nanorods. Chem. Comm., 2001, 14, 1264.

[9] Caswell, K.K.; Wilson, J.N.; Bunz, U.F.; Murphy, C.J. Preferential end-to-end assembly of gold nanorods by biotin-streptavidin. $J$. Am. Chem. Soc., 2003, 125, 13914.

[10] Chen, J.; Wiley, B.J.; Xia, Y. One-dimensional nanostructures of metals: Large-scale synthesis and some potential applications. Langmuir, 2007, 23, 4120.

[11] Shankar, S.S.; Rai, A.; Ahmad, A.; Sastry, M. Controlling the optical properties of lemongrass-extract synthesized gold nanotriangles and potential application in infrared-absorbing optical coatings. Chem. Mater., 2005, 17, 566. 
[12] Joshi, H.M.; Bhumakar, D.R.; Joshi, K.; Pokharkar, V.; Sastry, M. Gold nanoparticles as carriers for efficient transmucosal insulin delivery. Langmuir, 2006, 22, 300.

[13] Ahmad, A.; Senapati, S.; Khan, M.I.; Kumar, R.; Sastry, M. Extracellular biosynthesis of monodisperse gold nanoparticles by a novel extremophilic actinomycete, thermomonospora Sp. Langmuir, 2003, 19,3550 .

[14] Lu, X.; Yavuz, M.S.; Tuan, H.-Y.; Korgel, B.A.; Xia, Y. Ultrathin gold nanowire can be obtained by reducing polymeric strands of oleylamine- $\mathrm{AuCl}$ complexes formed via aurophilic interaction. $J$. Am. Chem. Soc., 2008, 130, 8900.

[15] Grabar, K.C.; Brown, K.R.: Kreating, C.D.; Stranick, S.J.; Tang, S.L.; Natan, M.J. Nanoscale characterization of gold colloid monolayers: A comparison of four techniques. J. Anal. Chem., 1997, 69, 471.

[16] Lim, B.; Camargo, P.H.C.; Xia, Y. Mechanistic study on the synthesis of Au nanotadpoles, nanokites, and microplates by reducing aqueous $\mathrm{HAuCl}_{4}$ with poly (Vinyl Pyrrolidone). Langmuir, 2008, 24, 10437.

[17] Shukla, S.; Priscilla, A.; Banerjee, M.; Bhonde, R.R.; Ghatak, J.; Satyam, P.V.; Sastry, M. Porous gold nanospheres by controlled transmetalation reaction: A novel material for application in cell imaging. Chem. Mater., 2005, 7, 5000.

[18] Thomas, K.G.; Kamat, P.V. Making Gold nanoparticles glow, enhanced emission from a surface bound probe. J. Am. Chem. Soc., 2000, 122, 2655.

[19] Madler, L.; Stark, W.J.; Pratsinis, S.E. Flame-made ceria nanoparticles. J. Mater. Res., 2002, 17, 1356.

[20] Wright, A.; Gabaldon, J.; Burckel, D.B.; Jiang, Y-B.; Tian, Z.R.; Liu, J.; Brinker, C.J.; Fan, H. Structured mesoporous tin oxide with electrical conductivity. Application in electroluminescence. Chem. Mater., 2006, 18, 3034.

[21] Pierrat, S.; Zins, I.; Breivogel, A.; Sonnichse, C. Self-assembly of small gold colloids with functionalized gold nanorods. Nano Lett., 2007, 7, 259.

[22] Thomas, K.G.; Barzzouk, S.; Ipe, B.I.; Shibu Joseph, S.T.; Kamat, P.V. Unidirectional plasmon coupling through longitudinal selfassembly of gold nanorods. J. Phys. Chem. B., 2004, 108, 13066.
[23] Schimd, G. Clusters and Colloids from Theory to Applications, VCH, New York. 1994.

[24] Henglein, A. Physicochemical properties of small metal particles in solution: "microelectrode" reactions, chemisorption, composite metal particles, and the atom-to-metal transition. J. Phys. Chem. 1993, 97, 5457.

[25] Belloni, J. Metal nanocolloids. Curr. Opin. Colloid Interface Sci., 1996, 1,184 .

[26] Umezawa, H.; Hooper, I.R. Aminoglycoside Antibiotics. (Eds.), Springer-Verlag: New York, Heidelberg, 1982.

[27] Mirkin, C.A.; Letsinger, R.L.; Mucic, R.C.; Storhoff, J.J. A DNAbased method for rationally assembling nanoparticles into macroscopic materials. Nature, 1996, 382, 607.

[28] Storhoff, J.J.; Mirkin, C.A. Programmed materials synthesis with DNA. Chem. Rev., 1999, 99, 1849.

[29] Klaus, T.; Joerger, R.; Olsson, E.; Granqvist, C-G. Silver-based crystalline nanoparticles, microbially fabricated. Proc. Natl. Acad. Sci. USA., 1999, 96, 13611.

[30] Konishi, Y.; Ohno, K.; Saitoh, N.; Nomura, T.; Nagamine, S.; Hishida, H.; Takahashi, Y.; Uruga, T. Bioreductive deposition of platinum nanoparticles on the bacterium shewanella algae. J. Biotechnol., 2007, 128, 648 .

[31] Nair, B.; Pradeep, T. Coalescence of nanoclusters and formation of submicron crystallites assisted by Lactobacillus strains. Cryst. Growth Des., 2002, 2, 293.

[32] Willner, I.; Baron, R.; Willner, B. Growing metal nanoparticles by enzymes. Adv. Mater., 2006, 18, 1109.

[33] Shankar, S.S.; Rai, A.; Ahmad, A.; Sastry, M. Rapid synthesis of $\mathrm{Au}, \mathrm{Ag}$, and bimetallic $\mathrm{Au}$ core-Ag shell nanoparticles using Neem (Azadirachta indica) leaf broth. J. Colloid Interface Sci., 2004, $275,496$.

[34] Chau, K.W., "Transverse mixing coefficient measurements in an open rectangular channel," Adv. Environ. Res., 2000, 4(4), 287.

[35] Chau, K.W., "Field measurements of SOD and sediment nutrient fluxes in a land-locked embayment in Hong Kong," Adv. Environ. Res., 2002, 6(2), 135.

[36] Chua, K.W., "Investigation on effects of aggregate structure in water and wastewater treatment," World Appl. Sci. J., 2004, 50(12), 119.

\begin{tabular}{lll}
\hline Received: September 03, 2011 & Revised: November 16, 2011 & Accepted: November 17, 2011
\end{tabular}

(C) Nalage et al.; Licensee Bentham Open .

This is an open access article licensed under the terms of the Creative Commons Attribution Non-Commercial License (http://creativecommons.org/licenses/by-nc/3.0/) which permits unrestricted, non-commercial use, distribution and reproduction in any medium, provided the work is properly cited. 